\title{
A genetic algorithm modelling of temperature distributions in the AZ31B magnesium alloys with 7075 aluminium alloy friction welded joints
}

\author{
Radosław Winiczenko ${ }^{1, *}$, Andrzej Sibicki ${ }^{2}$, Pawet Skoczylas ${ }^{3}$, and Jędrzej Trajer ${ }^{1}$ \\ ${ }^{1}$ Faculty of Production Engineering, Warsaw University of Life Sciences, Nowoursynowska 166, 02- \\ 787, Warsaw, Poland \\ ${ }^{2}$ Faculty of Mechanical Engineering, University of Science and Technology, Al. prof. S. Kaliskiego \\ 7, 85-796, Bydgoszcz, Poland \\ ${ }^{3}$ Faculty of Production Engineering, Warsaw University of Technology, Narbutta 85, 02-524, \\ Warsaw, Poland
}

\begin{abstract}
This paper presents a genetic algorithm modelling of temperature distribution during heating and cooling of AZ31B magnesium alloys with 7075 aluminium alloy friction welded joints. The temperature distributions estimated in the joints using K-type thermocouples with the accuracy of $\pm \square 0.1^{\circ} \mathrm{C}$. The thermocouples were installed in $1.2 \mathrm{~mm}$ holes at the periphery joint - 5, 10, and $15 \mathrm{~mm}$ from the weld interface. Temperature reading was performed with a digital thermometer with the requisition frequency of $1000 \mathrm{~Hz}$ during friction welding. Maximum temperature measurements in the half-radius of the analysed joints were equal to $305^{\circ} \mathrm{C}$ and $324^{\circ} \mathrm{C}$, for the AZ31B magnesium alloy and 7075 aluminium alloy specimens, respectively. Both temperature and increasing temperature gradient at the axial specimens were higher than those at the half-radius and periphery of the joints. The empirical models for heating $\mathrm{T}=a / b+\exp (c \mathrm{t})$ and cooling phases $\mathrm{T}=a-b \mathrm{t}^{c}$ were formulated by the authors of this study. These models used to describe the temperature curves of welding process. The goodness of fit of tested mathematical models to the experimental data was evaluated with the coefficient of determination $R^{2}$. A nonlinear regression analysis was conducted to fit the models by genetic algorithm (GA) using computer program MATLAB.
\end{abstract}

\section{Introduction}

Magnesium alloy has many advantages, such as low weight, high specific strength and rigidity, high heat and electrical conductivity [1]. To achieve mass production of magnesium alloys components, proper processes such as efficient joining technology will need to be developed [2]. As an engineering, wider applications of magnesium alloy in automative, electronics and aerospace industry, will meet the needs for dissimilar welding

\footnotetext{
*Corresponding author: radoslaw_winiczenko@sggw.pl
} 
of magnesium alloy to other metals like steel, copper or aluminium. Moreover, it is necessary to obtain a reliable joining process [3]. The welding of magnesium alloy to aluminum alloy has significant application in manufacturing industry, so the friction welding of magnesium alloy to aluminium alloy was studied in last paper. These components are joined by a variety of welding methods including tungsten arc inert gas [4], laser welding [5, 6], diffusion bonding [7,8], explosion welding [9], cold metal transfer friction [10], friction stir welding [11-13] and friction welding [14-18].

Friction welding is a widely accepted solid state joining process which has recently aroused interest in the aerospace industry for welding of dissimilar materials. The temperature at the interface between the metals must reach a suitable value, but be below the melting temperature. Axial temperature distribution and estimation of the heat flux in friction welding has been studied by many authors. More publications based on analytical $[19,20]$ and numerical solutions [21], such as the finite difference method and finite element method, are presented. The estimation of temperature distribution in the friction welding of ductile iron with mild steel bars was also achieved [22]. The relationship between mechanical and heat energy was carried out in a paper [23].

The aim of this article is time-temperature curves modelling of magnesium-aluminium alloys weld using a genetic algorithm method. In this study, an experimental study determination of temperature during friction welding process of magnesium alloys with aluminium alloys. Estimating the thermal field developed in a friction welded of AZ31B7075 joint make it much easier to control the friction welding process by reducing the number of necessary experiments.

\section{Experimental procedure}

The specimens having the shape of bars of $20 \mathrm{~mm}$ in diameter and $100 \mathrm{~mm}$ in length were cut for welding process. The friction welding was done on magnesium alloy (AZ31B) with aluminium alloy (AA7075-T6) bars. The chemical composition of materials were presented in Table 1.

Table 1. Alloying elements (wt.\%) of base material.

\begin{tabular}{|c|c|c|c|c|c|c|c|}
\hline \multirow{2}{*}{ Material } & \multicolumn{7}{|c|}{ Chemical composition } \\
\cline { 2 - 8 } & $\mathrm{Mg}$ & $\mathrm{Al}$ & $\mathrm{Zn}$ & $\mathrm{Cu}$ & $\mathrm{Si}$ & $\mathrm{Mn}$ & $\mathrm{Fe}$ \\
\hline AA7075 & 2.25 & Rest & 5.67 & 1.62 & 0.17 & 0.14 & 0.29 \\
\hline AZ31B & Rest & $2.5-3.5$ & $0.6-1.4$ & 0.01 & 0.08 & $0.2-1.0$ & 0.003 \\
\hline
\end{tabular}

The surface of specimens for welding were prepared by means of using an abrasive cut-off machine. The process of joining was carried out on a continuous drive friction machine of the ZT4-13 type. The welding parameters such as friction pressure $(\mathrm{FP}=111 \mathrm{MPa})$, upsetting pressure $(\mathrm{UP}=127 \mathrm{MPa})$ and friction time $(\mathrm{FT}=13 \mathrm{~s})$ were employed in this study. The parameters were continuously monitored and recorded. Additionally, constant rotational speed $(\mathrm{RS}=1,450 \mathrm{rpm})$ and upsetting time (UT=6s) are used in welding process. Friction welding process of magnesium alloy with aluminium alloy with the thermocouple positions is shown in Fig. 1. 


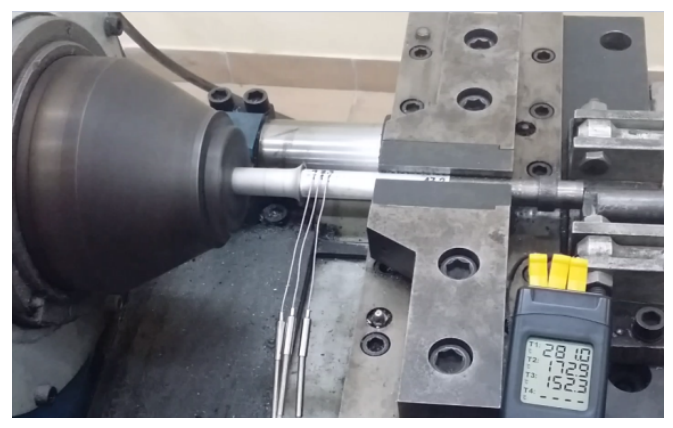

Fig. 1. Experimental setup on aluminium alloy side during friction phase of welding process.

The thermocouples were installed on a non-rotating part in $1.2 \mathrm{~mm}$ holes in the axis and half-radius of a joint at the different distances from the interface. The thermocouples were beaded at the tip and stuck at the measuring points with a silicate high temperature glue. Temperature identifiable in a close proximity to the interface of the joints was obtained with a TP202K1b2001 K-type thermocouple (NiCr-NiAl), with the accuracy of $\pm \square 0.1^{\circ} \mathrm{C}$. Temperature reading was performed with a UT 325 digital thermometer with the requisition frequency of $1000 \mathrm{~Hz}$ during friction welding. The temperature measurements of joints were monitored until the temperature decreased to level below room temperature. The schematic representation on the arrangement of fixing thermocouples is shown in Fig. 2.

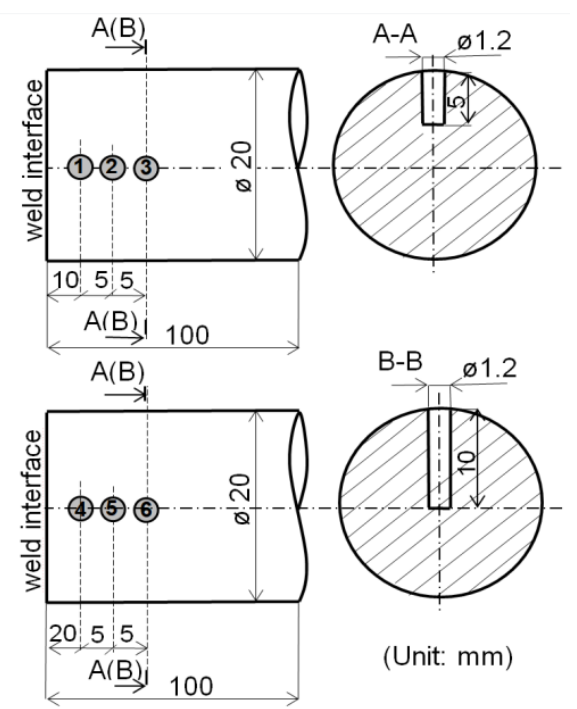

Fig. 2. The specimens geometry and thermocouples settings in the material.

\section{Results and discussion}

\subsection{Time-temperature distribution during heating process}

The process of temperature modelling during friction welding can be divided into two stages. Heating period and cooling period. During the heating period, intensive rubbing of the welded sample ends takes place. It is a period of mutual friction. After this period, the 
speed is stopped and formed by pressing the material. This is the upsetting period. As a result of clamping, a flash is formed. After the period of the bonding, there is a period of continuous cooling in the air [22].

Time-temperature profiles on the welding materials are shown in Fig. 3 and 4. Moreover, time-temperature curves were separated on the heating and cooling phases. As indicated by all of the thermocouple measurements, the analysed metal experienced a quickly rise in temperature to a peak value during welding. The peak heating temperature at $\mathrm{x}=10 \mathrm{~mm}$ from the interface was $324{ }^{\circ} \mathrm{C}$ (see Fig. 3) for welding time $\mathrm{t}=14 \mathrm{~s}$. The peak heating temperature at $\mathrm{x}=20 \mathrm{~mm}$ from the interface was $305{ }^{\circ} \mathrm{C}$ (see Fig. 4) for welding time $\mathrm{t}=14$ $\mathrm{s}$. The temperature maximum temperature value observed on aluminium alloy side at the half-radius was slightly higher than that of magnesium alloy side. The temperatures reached peak values, but did not exceed the melting temperature of $640^{\circ} \mathrm{C}$ for aluminium alloy, and $600^{\circ} \mathrm{C}$ for magnesium alloy, respectively.

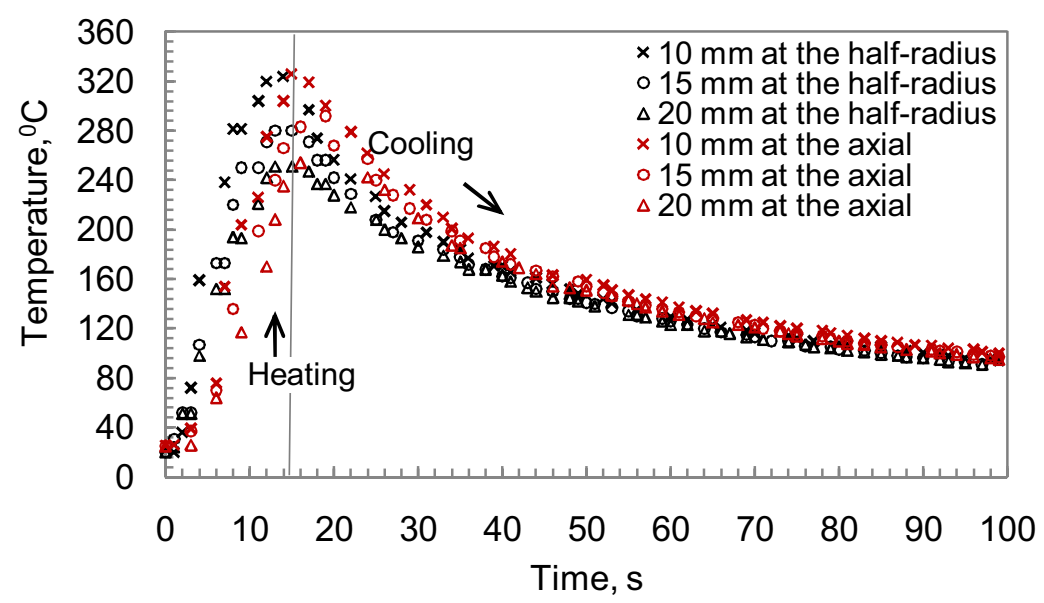

Fig. 3. The time-temperature profiles during friction welding on aluminium alloy side.

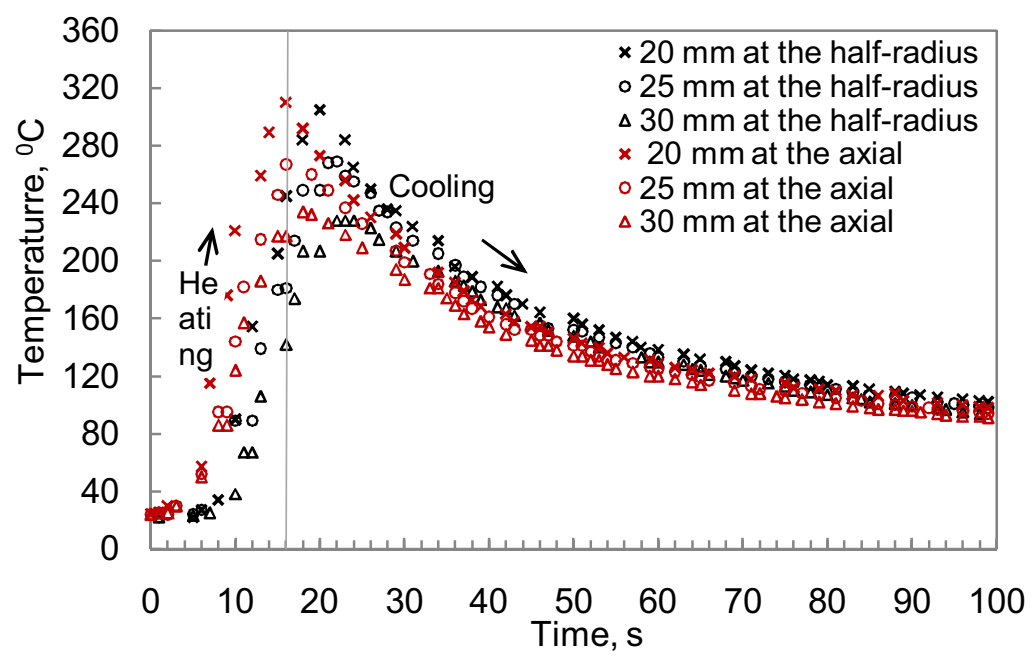

Fig. 4. The time-temperature profiles during friction welding on magnesium alloy side. 


\subsection{Time-temperature distribution during cooling process}

After the friction stage, the forging stage began and the metal cooled down gradually. During the cooling phase, heat was conducted away from the weld interface and lost to the surroundings through the ends of weld specimens $[22,24]$. At $14 \mathrm{~s}$, temperature started gradually dropping to $130^{\circ} \mathrm{C}$ after $60 \mathrm{~s}$, while at the location of $\mathrm{x}=20 \mathrm{~mm}$ from the interface, the peak heating temperature was $250^{\circ} \mathrm{C}$ (Fig. 3). It can be seen from Fig. 4 that all three curves show a very similar cooling behaviour below approximately $160^{\circ} \mathrm{C}$. The temperature curves of the aluminium side and magnesium side during cooling phase (Fig. 3 nad 4) clearly show that temperature close to the interface are higher than that of the peripheral zone at beginning of cooling phase. The cooling curve appears to be broader than heating curve, since rate of cooling is relatively slow. The similar curve profile received in the paper [18]. The heating and cooling rates of the welding process are approximately calculated around 22 and $2.6{ }^{\circ} \mathrm{C} / \mathrm{s}$ for AA7075 and 19 and $2.6{ }^{\circ} \mathrm{C} / \mathrm{s}$ for AZ31B alloy at the axial specimen, respectively.

\section{Mathematical modelling}

\subsection{Modelling of temperature curves for welding process}

The empirical models for the heating $T=\frac{a}{b+\exp \left(c^{\cdot} t\right)}$ and cooling stages $T=a-b^{\cdot} t^{c}$ were used to describe the temperature curves of welding process; where $a, b$, and $c$ are the constants of the models; $\mathrm{t}$ is the welding time, $\mathrm{s}$; $\mathrm{T}$ is calculated temperature, ${ }^{0} \mathrm{C}$.

The constants of the models and the coefficient of determination $R^{2}$ are shown in Table 2-5. The goodness of fit of tested mathematical models to the experimental data was evaluated with the coefficient of determination $R^{2}$. The higher $R^{2}$ the better is the goodness of fit the models. A nonlinear regression analysis was conducted to fit the models by genetic algorithm using Optimization Toolbox computer program in the MATLAB 7.0 software.

Table 2. Mathematical models of temperature curves for heating process during welding on aluminium alloy side.

\begin{tabular}{|c|c|c|c|}
\hline $\begin{array}{c}\text { Thermocouple } \\
\text { No. }\end{array}$ & $\begin{array}{c}\text { Distance } \\
\mathrm{x}(\mathrm{mm})\end{array}$ & $\begin{array}{c}\text { Mathematical model } \\
R^{2}\end{array}$ & 0.9924 \\
\hline 1 & 5 & $T=\frac{12.58}{0.0408+\exp \left(-1.062^{\circ} \mathrm{t}\right)}$ & 0.9859 \\
\hline 2 & 10 & $T=\frac{11.58}{0.0379+\exp \left(-1.119^{\circ} \mathrm{t}\right)}$ & 0.9863 \\
\hline 3 & 15 & $T=\frac{24.41}{0.0962+\exp \left(-0.419^{\circ} \mathrm{t}\right)}$ & 0.9926 \\
\hline 4 & 5 & $T=\frac{19.17}{0.0562+\exp \left(-0.543^{\circ} \mathrm{t}\right)}$ & 0.9922 \\
\hline 5 & 10 & $T=\frac{17.00}{0.0623+\exp \left(-0.923^{\circ} \mathrm{t}\right)}$ & 0.13 .13 \\
\hline 6 & 15 & $T=\frac{13}{0.0545+\exp \left(-0.946^{\circ} \mathrm{t}\right)}$ & 0.9824 \\
\hline
\end{tabular}


Table 3. Mathematical models of temperature curves for heating process during welding on magnesium alloy side.

\begin{tabular}{|c|c|c|c|}
\hline $\begin{array}{c}\text { Thermocouple } \\
\text { No. }\end{array}$ & $\begin{array}{c}\text { Distance } \\
\mathrm{x}(\mathrm{mm})\end{array}$ & $\begin{array}{c}R \text {-squared } \\
R^{2}\end{array}$ \\
\hline 1 & 20 & $T=\frac{3.133}{0.0097+\exp \left(-0.738^{\circ} \mathrm{t}\right)}$ & 0.9935 \\
\hline 2 & 25 & $T=\frac{5.36}{0.0192+\exp \left(-0.397^{\circ} \mathrm{t}\right)}$ & 0.9844 \\
\hline 3 & 30 & $T=\frac{3.275}{0.0125+\exp \left(-0.373^{\circ} \mathrm{t}\right)}$ & 0.9794 \\
\hline 4 & 20 & $T=\frac{17.44}{0.0465+\exp \left(-0.428^{\circ} \mathrm{t}\right)}$ & 0.9926 \\
\hline 5 & 25 & $T=\frac{12.39}{0.0373+\exp \left(-0.335^{\circ} \mathrm{t}\right)}$ & 0.9836 \\
\hline 6 & 30 & $T=\frac{12.55}{0.0465+\exp \left(-0.329^{\circ} \mathrm{t}\right)}$ & 0.9832 \\
\hline
\end{tabular}

Table 4. Mathematical models of temperature curves for continuous cooling process on aluminium alloy side.

\begin{tabular}{|c|c|c|c|}
\hline $\begin{array}{c}\text { Thermocouple } \\
\text { No. }\end{array}$ & $\begin{array}{c}\text { Distance } \\
\mathrm{x}(\mathrm{mm})\end{array}$ & Mathematical model & $\begin{array}{c}R \text {-squared } \\
R^{2}\end{array}$ \\
\hline 1 & 5 & $T=1483-954^{\cdot} t^{0.0917}$ & 0.9587 \\
\hline 2 & 10 & $T=1953-1447^{\prime} \cdot t^{0.0603}$ & 0.9639 \\
\hline 3 & 15 & $T=1360-911^{\cdot} t^{0.0786}$ & 0.9834 \\
\hline 4 & 5 & $T=2423-1837^{\prime} \cdot t^{0.0521}$ & 0.9717 \\
\hline 5 & 10 & $T=1722-1194 \cdot t^{0.0682}$ & 0.9743 \\
\hline 6 & 15 & $T=1045-591^{\circ} t^{0.1046}$ & 0.9834 \\
\hline
\end{tabular}

Table 5. Mathematical models of temperature curves for continuous cooling process on magnesium alloy side.

\begin{tabular}{|c|c|l|l|}
\hline $\begin{array}{c}\text { Thermocouple } \\
\text { No. }\end{array}$ & $\begin{array}{c}\text { Distance } \\
\mathrm{x}(\mathrm{mm})\end{array}$ & Mathematical model & $\begin{array}{l}R \text {-squared } \\
R^{2}\end{array}$ \\
\hline 1 & 20 & $T=2313-1732 \cdot t^{0.0581}$ & 0.9062 \\
\hline 2 & 25 & $T=1172-638.6^{\prime} t^{0.1211}$ & 0.9490 \\
\hline 3 & 30 & $T=637.9-234.2 \cdot t^{-0.1958}$ & 0.9685 \\
\hline 4 & 20 & $T=2133-1596 \cdot t^{0.0544}$ & 0.9472 \\
\hline 5 & 25 & $T=2538-2038^{\circ} t^{0.0405}$ & 0.9675 \\
\hline 6 & 30 & $T=1113-686^{\cdot} t^{-0.0887}$ & 0.9743 \\
\hline
\end{tabular}

\subsection{Genetic algorithm parameters}

Genetic algorithms (GA) are a search optimization technique based on a natural selection process that mimics biological evolution [25]. The GA has been applied in many complex optimization and search problems, outperforming traditional optimization and search methods. The basic genetic algorithm contains the following steps: (A) selection of the initial population chromosome, (B) fitness function calculation, (C) checking stopping criterion, (D) selection of chromosomes, (E) application of crossover and mutation 
operators, $(\mathrm{F})$ creating a new population, $(\mathrm{G})$ return to step $\mathrm{B}$, and $(\mathrm{H})$ the best chromosome presentation [26]. The mathematical functions formulated for heating and cooling stages are then used to measure the fitness value for each chromosome in the algorithm procedure.

The main genetic algorithm parameters were: population size, number of generations, crossover probability, and mutation probability. In this study, a population size of 80 , crossover probability of 0.8 , mutation probability of 0.2 , and number of iteration of 500 were employed.

\subsection{Modelling and the maximum temperature calculation at the interface}

The predicted of maximum temperature curves at the weld interface are shown in Figs. 5-8.

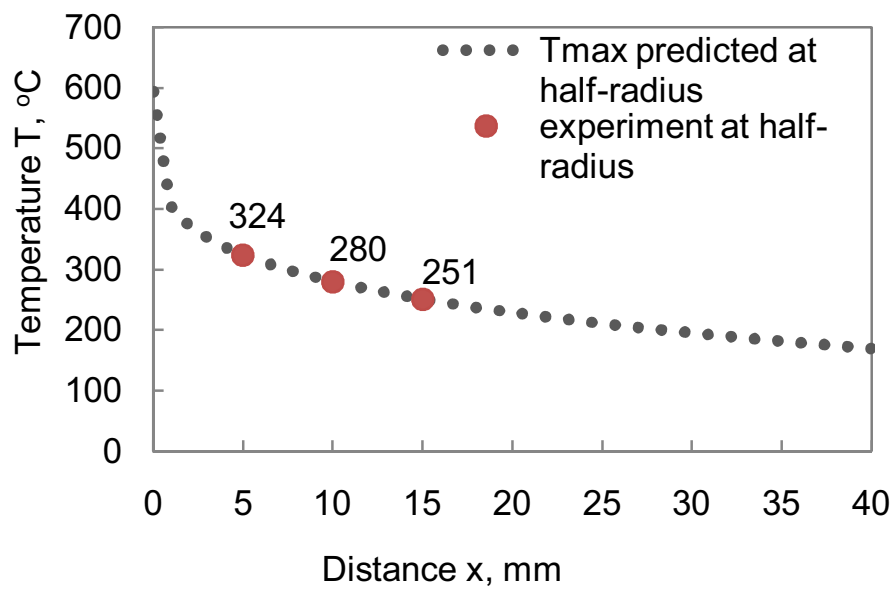

Fig. 5. The predicted of maximum temperature curves at half-radius on aluminium alloy side.

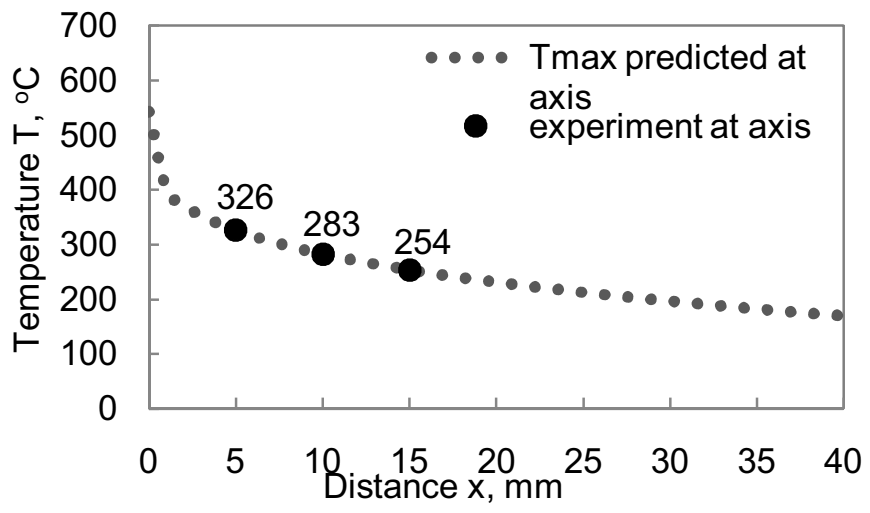

Fig. 6. The predicted of maximum temperature curves at axis on aluminium alloy side. 


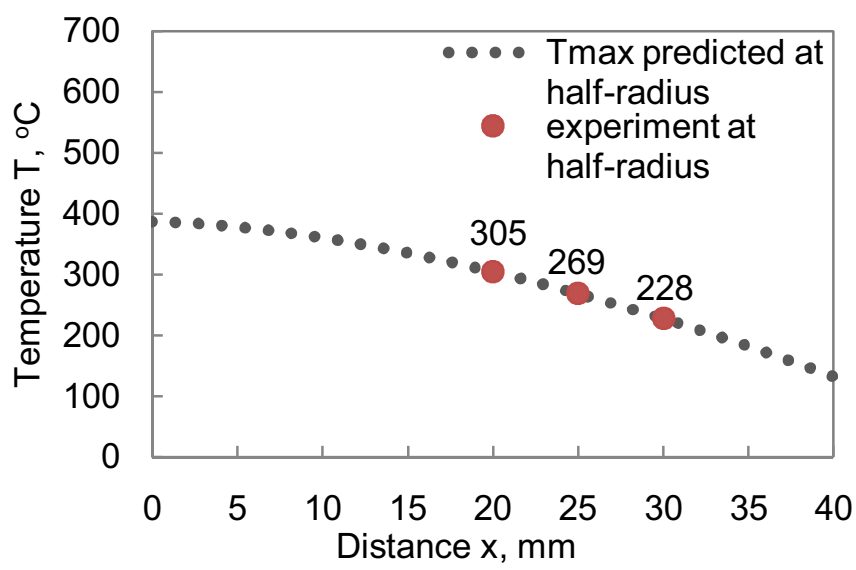

Fig. 7. The predicted of maximum temperature curves at half-radius on magnesium alloy side.

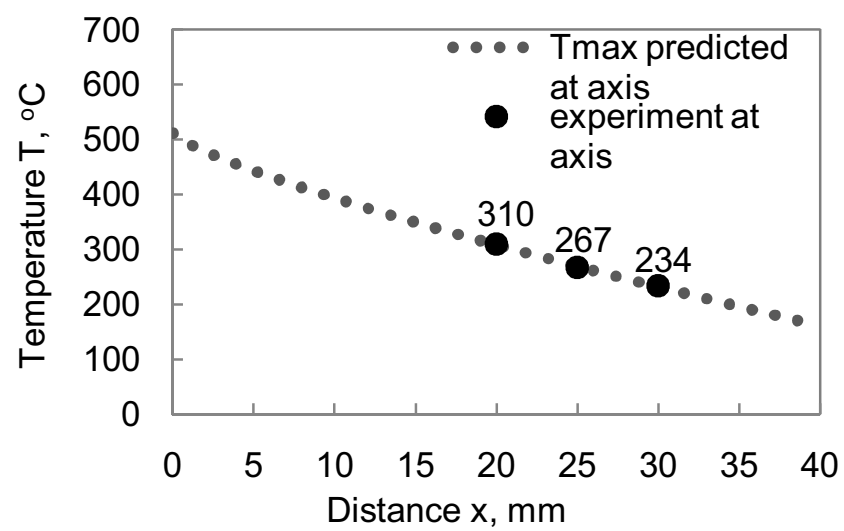

Fig. 8. The predicted of maximum temperature curves at axis on magnesium alloy side.

It can be seen from Fig. 5-8, that the maximum temperatures at half-radius and the axis of specimen friction welded joints amounted to $593^{\circ} \mathrm{C}$ and $543^{\circ} \mathrm{C}$ for aluminum alloy and $386^{\circ} \mathrm{C}$ and $511^{\circ} \mathrm{C}$ for magnesium alloy, respectively. The peak temperature of magnesium alloy was lower than temperature estimated on aluminium alloy side. Moreover, four peak temperature are lower than the melting point of materials.

The constants of the models and the coefficient of determination $R^{2}$ calculate by genetic algorithm are shown in Table 5.

Table 5. The mathematical equations for estimation of peak temperature at the interface.

\begin{tabular}{|l|l|c|l|l|}
\hline Material & Position & $\begin{array}{c}\text { Distance } \\
\mathrm{x}(\mathrm{mm})\end{array}$ & Mathematical model & $\begin{array}{c}R \text {-squared } \\
R^{2}\end{array}$ \\
\hline AA7075 & half-radius & $10,15,20$ & $T=593-189.5 \cdot t^{0.218}$ & 0.9862 \\
\hline AA7075 & axial & $10,15,20$ & $T=543-142 \cdot t^{0.260}$ & 0.9998 \\
\hline AZ31B & half-radius & $20,25,30$ & $T=386-0.582 \cdot t^{1.647}$ & 0.9790 \\
\hline AZ31B & axial & $20,25,30$ & $T=511-19.3 \cdot t^{0.785}$ & 0.9960 \\
\hline
\end{tabular}


The maximum temperature value at the weld interface ( for $\mathrm{x}=0$ ) were estimated using empirical model $T=a-b \cdot x^{c}$; where $\mathrm{a}, \mathrm{b}$, and $\mathrm{c}$ are the constants of the models; $\mathrm{x}$ is a distance from weld interface, $\mathrm{mm}$; $\mathrm{T}$ is calculated maximum temperature, ${ }^{0} \mathrm{C}$.

\section{Conclusions}

The temperature variations during the friction welding process were studied both numerically and experimentally. The empirical models for heating $T=\frac{a}{b+\exp \left(c^{*} \mathrm{t}\right)} \quad$ and cooling stages $T=a-b \cdot t^{c}$ were proposed by the authors of this study. Furthermore, the maximum temperature values at the weld interface for $\mathrm{x}=0$ were estimated using empirical model $T=a-b \cdot \mathrm{x}^{c}$. The proposed models were used to describe the temperature curves of welding process of light metals. The maximum temperatures in the friction welded joints were close to $593^{\circ} \mathrm{C}$ for aluminium and $511^{\circ} \mathrm{C}$ for magnesium alloy, respectively. The peak temperatures are lower than the melting point of magnesium and aluminium alloy. The maximum temperature of aluminium side is higher than temperature measured on the magnesium side. The peak temperature and rate during cooling of samples have significant effect on the mechanical properties of the joints.

\section{References}

1. L. Liu, Welding and joining of magnesium alloys, Woodhead Publishing Limited, Cambridge, (2010).

2. K.M. Hong, Y.C Shin, J. Mat. Process. Technol. 24546 (2017).

3. L Liu, D Ren, F Liu, Materials, 7, 3735 (2014).

4. P. Liu, Y. Li, H. Geng, J. Wang, Mater Lett, 611288 (2007).

5. R. Borrisutthekul, Y. Miyashita, Y. Mutoh, Sci. and Techn. of Adv. Mater, 6 (2005).

6. Liu Lm, Zhao X, Mater. Character, 59, 1279 (2008).

7. P. Liu, Y. Li, J. Wang, M.A. Haijun, G. Guo, H. Geng, Metall. Mater. Trans. B, 37, 649 (2006).

8. L.M. Zhao, Z.D. Zhang, Scr. Mater, 58, 283 (2008).

9. Y.B. Yan, Z.W. Zhang, W. Shen, J.H Wang, L.K. Zhang, B.A. Chin, Mater. Sci. Eng. A, 527, 2241 (2010).

10. R. Cao, B.F. Wen, J.H. Chen, P.C. Wang, Mater. Sci. Eng. A, 560, 256 (2013).

11. A.A. Mclean, G.L.F. Powell, I.H. Brown, V.M. Linton, Sci. Techn. Weld. Join, 8, 462 (2003).

12. V. Firouzdor, S. Kou, Metall. Mater. Trans: A, 412914 (2010).

13. B. Fu, G. Qin, F. Li, X. Meng, J. Zhang, C. Wu, J. Mat. Process. Technol. 218, 38 (2015).

14. K. Kato, H. Tokisue, Weld. Intern. 18, 861 (2004).

15. M. Kimura, A. Fuji, S. Shibata, Mat. Design. 85, 169 (2015).

16. Z. Liang, G. Qin, L. Wang, X. Meng, F. Li, Mater. Sci. Eng. A 645, 170 (2015).

17. Z. Liang, G. P. Qin, F. Geng. X. Yang, Meng, J. Manuf. Processes, , 25, 153 (2017).

18. Guo W, You G, Yuan G, Zhang X, J. Alloys Compd, 695, 3267 (2017).

19. V. I Vill, Friction welding of metals (AWS, New York, 1962).

20. T. Rich, R. Roberts, Met. Constr. Brit. Weld. J., March, 93 (1971). 
21. N.N. Rykalin, A.J. Pugin, V.A. Vasil'eva, Weld. Prod, 42 (1959).

22. R. Winiczenko, M. Kaczorowski, A. Skibicki, J. Braz. Soc. Mech. Sci, 40, 347 (2018).

23. A. Can, M. Sahin, M. Kucuk M, Strojar. 51, 5 (2009).

24. American Welding Society, Recommended practice for friction welding (AWS, Miami, 1989).

25. Gen M, Cheng R Genetic algorithm and engineering optimization (John Wiley \& Sons, Inc., 2000).

26. D.E, Goldberg, Genetic algorithm in search, optimization and machine learning (Addison-Wesley, Reading, 1989). 